This item was submitted to Loughborough's Research Repository by the author.

Items in Figshare are protected by copyright, with all rights reserved, unless otherwise indicated.

\title{
Summertime impact of climate change on multi-occupancy British dwellings
}

PLEASE CITE THE PUBLISHED VERSION

PUBLISHER

(C) Open House International Association

VERSION

VoR (Version of Record)

LICENCE

CC BY-NC-ND 4.0

\section{REPOSITORY RECORD}

Shikder, Shariful H., Monjur Mourshed, and Andrew D.F. Price. 2019. "Summertime Impact of Climate Change on Multi-occupancy British Dwellings”. figshare. https://hdl.handle.net/2134/11555. 
This item was submitted to Loughborough's Institutional Repository (https://dspace.lboro.ac.uk/) by the author and is made available under the following Creative Commons Licence conditions.

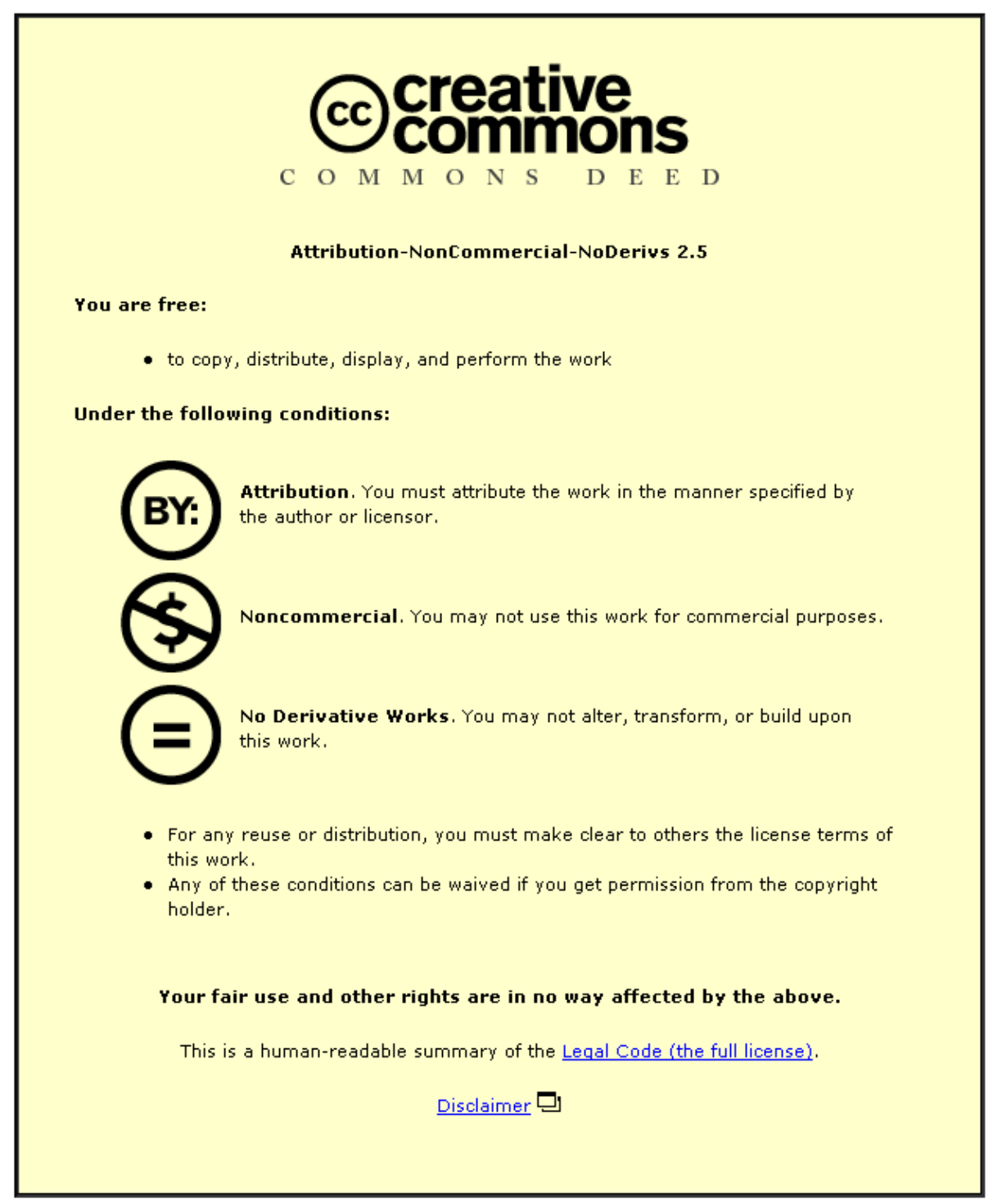

For the full text of this licence, please go to: http://creativecommons.org/licenses/by-nc-nd/2.5/ 


\title{
SUMMERTIME IMPACT OF CLIMATE CHANGE ON MULTI-OCCUPANCY BRITISH DWELLINGS
}

\author{
Shariful Shikder, Monjur Mourshed, Andrew Price
}

\begin{abstract}
Recent climate change projections estimate that the average summertime temperature in the southern part of Great Britain may increase by up to $5.4^{\circ} \mathrm{C}$ by the end of the century. The general consensus is that projected increases in temperature will render British dwellings vulnerable to summer overheating and by the middle of this century it may become difficult to maintain a comfortable indoor environment, if adaptation measures are not well integrated in the design and operation of new dwellings, which are likely to remain in use beyond the 2050s. The challenge is to reduce overheating risks by integrating building and user adaptation measures, to avoid energy intensive mechanical cooling. Developing guidelines and updating building regulations for adaptation, therefore, requires an understanding of the baseline scenario; i.e. the performance of existing buildings in future climates.

This paper aims to investigate the performance of new-build multi-occupancy British dwellings for human thermal comfort in the present-day and projected future climates in four regional cities: Birmingham, Edinburgh, London and Manchester. Evaluations are carried out by a series of dynamic thermal simulations using widely adopted threshold temperature for overheating, as well as adaptive thermal comfort standards. This study thus offers a unique perspective on regional variations of performance and provides a clearer snapshot because of the use of more appropriate adaptive comfort standards in the evaluations. Finally, the paper sheds light on possible personal and building adaptation measures to alleviate overheating risks.
\end{abstract}

Keywords: Adaptive thermal comfort, climate change, adaptation, thermal performance, building simulation.

\section{INTRODUCTION}

In light of compelling evidence for rapid anthropogenic climate change, there is a gradual shift towards adapting buildings and cities to the inevitable climate change, while mitigating its impacts. The basis for investigating climate change impact, vulnerability and adaptation in the UK is the scenarios projected by the United Kingdom Climate Impacts Programme (UKCIP). The projected UKCIP medium emissions scenario suggests that average summer temperature will increase by up to $5.4^{\circ} \mathrm{C}$ in the southern part of England by 2080s (Murphy et al. 2009). Concerns over rising temperature has, therefore, resulted in a growing awareness of the need for embedding adaptation in the design and operation of a building in the UK and around the globe. A number of recent publications, including the ones from the Chartered Institution of Building Services Engineers (CIBSE) (CIBSE 2005) have investigated the impact of climate change in buildings, indicating that the UK has a high probability of experiencing overheating in buildings in future.

\section{BRITISH DWELLINGS AND NEED FOR ADAPTATION}

A significant number of new dwellings are built every year in the Britain. According to the Department for Communities and Local Government (DCLG), 1.6 million new dwellings were built in the UK between 1997 and 2006. Although new construction has fallen since the economic downturn, it is expected to be temporary. The household numbers are also projected to grow to 27.8 million in 2033 - an increase of $5.8 \%$, compared to 2008 (DCLG 2009). Increasing household numbers will require additional dwellings to be built, which will constitute a significant part of the total dwelling stock in coming decades. Moreover, there is a tendency in the UK towards building flats in multi-occupancy buildings rather than singleoccupancy traditional houses. Flats accounted for $46 \%$ of total new dwellings in 2008-09 (DCLG 2009).

British dwellings are mostly naturally ventilated and heating dominated, which can make 
them vulnerable during hot weather or sudden heat waves, in particular in future climates with increased temperatures. According to CIBSE (2005), it will be difficult to maintain indoor conditions within comfort zone in many residential buildings, in particular in bedrooms, in some parts of the country. Therefore, the challenge is to adapt to the warming climate without the aid of energy-intensive mechanical cooling. Understanding the performance of the new-build dwellings in future climates is the logical first step in developing strategies and guidelines for adaptation.

\section{THERMAL COMFORT ASSESSMENT METHODS}

A key issue while investigating the thermal performance is the evaluation criteria used in previous studies. CIBSE has published several guidelines on environmental and design of buildings in current and projected climates. CIBSE $(2005,2006)$ recommended temperature benchmarks or thresholds to identify building overheating. One of the key criticisms is that this temperature threshold remains same, irrespective of the time of year and geographical location. Past research on thermal comfort suggests that the comfort range is significantly influenced by the outside temperature and people can adapt to a wider range of temperatures depending on their thermal experience of previous days and available adaptation opportunities (de Dear and Brager 1998; Nicol and Humphreys 2002). This provides a wider range of acceptable temperatures specifically for naturally ventilated buildings, also known as adaptive thermal comfort standards (ASHRAE 2010; BS 2007).

\section{AIM AND OBJECTIVES}

This paper aims to investigate the performance of new-build multi-occupancy British dwellings for human thermal comfort in the present-day and projected future climates in four regional cities: Birmingham, Edinburgh, London and Manchester. Evaluations are carried out by a series of dynamic thermal simulations using widely adopted threshold temperature for overheating, as well as adaptive thermal comfort standards. This study thus offers a unique perspective on regional variations of performance and provides a clearer snapshot because of the use of more appropriate adaptive comfort stan- dards in the evaluations. Finally, the paper sheds light on possible personal and building adaptation measures to alleviate overheating risks.

\section{PREVIOUS STUDIES AND ADAPTATION STRATEGIES}

A considerable number of studies have identified the impact of climate change on buildings thermal performance and energy demand (CIBSE 2005; Holmes and Hacker 2007; Jentsch et al. 2008; de Wilde and Tian 2010, 2012; Lomas and Giridharan 2011; Mourshed 2011; Gupta and Gregg 2012). Although earlier studies have only considered the simple overheating criteria proposed by CIBSE, there is considerable interest among researchers to explore the application of adaptive thermal comfort standards in this domain and has been applied in later studies. Previous publications also discussed various adaptive opportunities to mitigate the impact of overheating. The type of adaptive opportunities can be divided into two groups, one is directly associated with the occupant behaviour and activity; the other one is adaptation opportunity/measures of the building. Studies revealed that the infiltration rate is one of the most important design factors in defining the annual heating and cooling loads. In addition, other passive design strategies such as building materials, solar gain controls, etc. needs to be considered (CIBSE 2005; Hamilton-MacLaren et al. 2012; Holmes and Hacker 2007; Mourshed et al. 2005). Although most previous studies have discussed the adaptation of building itself, aspects related to occupants' behavioural adaptation have not been addressed in detail. However there is a considerable amount of personal adaptive opportunities that may be helpful in controlling building overheating. Key personal adaptive opportunities are related to the occupant's ability to open windows, control solar glare, turn lights off, use portable fan and change clothing, as well as individual control of HVAC rather than group control. In few cases, personal adaptive opportunities and building adaptation measures are closely linked. For example, if an occupant intends to open windows during hot weather, the building must be equipped with operable windows to facilitate this.

\section{SIMULATION MODEL}

The selected case study is a new two-storey purpose-built residential building containing two iden- 

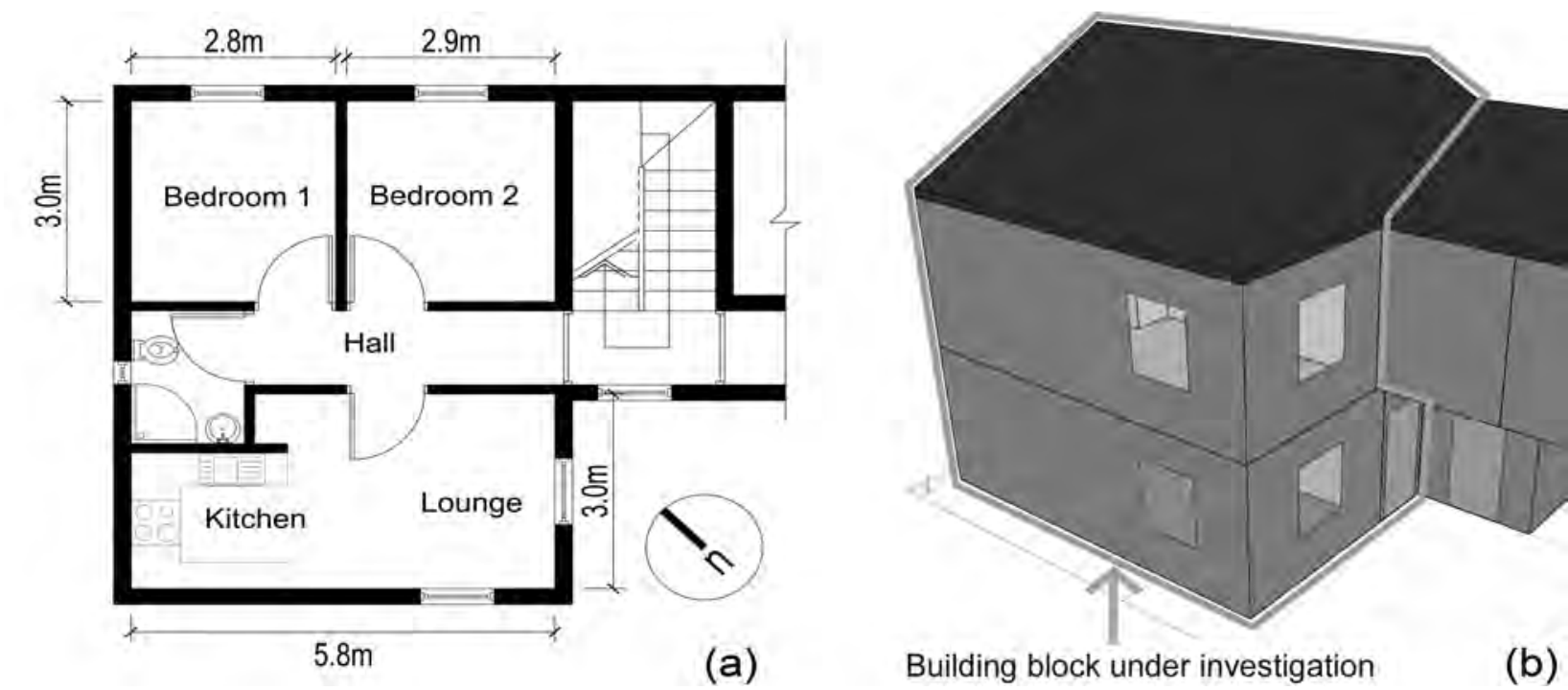

Figure 7. The case study building. (a) Plan. (b) 3D simulation model.

tical flats in each of the two floors. Each flat comprised two bedrooms, one hall, one bathroom and one open-plan kitchen and a lounge (Figure 1a). The building was specified to satisfy the requirements of the current building regulations, specifically Part L1A (NBS 2010).

The tool selected for the study is Autodesk Ecotect Analysis 2010, a whole building simulation program. The software uses the CIBSE Admittance Method to calculate heating and cooling loads for individual zones. Further, it can calculate direct and indirect solar gains, internal gains, inter-zonal heat flow, hourly internal temperatures, various loads breakdowns, impact of thermal mass and annual temperature distributions, etc. (Autodesk 2012). Simulation parameters for this study are discussed below.

U-value: U-values of the materials satisfy the requirements of current building regulations for new dwellings, as stipulated in the Approved Document L1A (NBS 2010).

Internal gains: Internal heat gain values were acquired from CIBSE Guide A (2006) to apply in the simulation model. A sensible and latent heat gains for human for seated/sedentary works were considered 70 and $45 \mathrm{~W}$ respectively. Table 1 states the rate of heat gains considered for this study. This data was used to derive the internal gains $(\mathrm{W} / \mathrm{m} 2)$ for each zone.

Air change rate: In this study air change rate per hour $(\mathrm{ACH})$ is used to define the infiltration and ventilation rate of the building. Selected flats are naturally ventilated and with heating provisions to run during winter. Depending on the window size in open states, $\mathrm{ACH}$ can vary from 0.5 to 10 in

\begin{tabular}{|l|l|r|r|}
\hline Room/Zone & Equipment & $\begin{array}{l}\text { Rate of heat gains } \\
\text { (W) }\end{array}$ & Operation hours \\
\hline Bed1 & Light & 18 & $2000-0100$ \\
& Laptop & 50 & $2100-2300$ \\
& Small TV/monitor & 50 & $2100-2200$ \\
\hline Bed2 & Light & 18 & $2000-2300$ \\
& Desktop computer with & 250 & $2100-2200$ \\
& monitor & & \\
\hline Lounge+ Kitchen & Light. & 36 & $1900-0000$ \\
& Range & 1280 & $1900-2000$ \\
& Microwave over & 1000 & $2000-2030$ \\
& Toaster & 790 & $0700-0800$ \\
& Reffigerator (small) & 350 & $0000-0000$ \\
& Water supply & 37 & $1800-0900$ \\
\hline
\end{tabular}

Table 1. Internal heat gains of various rooms.

small-scale residential buildings. Cross ventilation typically results in higher the $\mathrm{ACH}$. $\mathrm{ACH}$ can be calculated using equation (1),

$$
n=3600 \times \frac{q}{v}
$$

where, = air change rate per hour, $q=$ fresh air flow through the room $\left(\mathrm{m}^{3} / \mathrm{s}\right)$, and $v=$ volume of the room $\left(\mathrm{m}^{3}\right)$.

Again air flow rate $\left(Q_{w}\right)$ for a single aperture in a room can be calculated by the following equation (2):

$$
Q_{W}=0.025 \times A \times V_{W}
$$

where $Q_{W^{\prime}}$ is the air flow rate per hour, $A$ is the area of the apertures and $V_{W}$ is the wind velocity. Average air change rate for first floor and ground floor bedroom are 2.83 and 2.34 respectively. This was calculated using Equation (1) and (2) considering the open-able window area of $0.5 \mathrm{~m} 2(1.10$ $\mathrm{m} 2$ total glazing area) and average outside wind velocity of $1.80 \mathrm{~m} / \mathrm{s}$. 
$\mathrm{ACH}$ is highly variable depending on the aperture of the opening, outside wind velocity and ventilation system of the building. There can be higher $\mathrm{ACH}$ during hot weather compared to winter as windows are usually open for longer period during hot weather. In this study $\mathrm{ACH}$ ranged from 2 to 10 have been used to evaluate the building thermal performance. $\mathrm{ACH}$ was modelled by the approximate percentage of window opening and closed states, where 100\% indicates window was fully open. It was considered the window was open for 14 hours (1800 to 0800) in a day during hot weather.

\section{WEATHER DATA}

CIBSE developed two types of standard weather data files for use in building performance assessment: Test Reference Year (TRY) for systems planning and Design Summer Year (DSY) for summer overheating prediction and analysis (CIBSE 2005). Current climate DSY weather files were adopted in this study, which was then used to generate projected weather data using the tool Climate Change Weather Generator (CCWeatherGen) (Jentsch et al. 2008).

\section{ANALYSIS METHODS \\ Overheating criteria}

Definition of the overheating criteria is based on acceptable operative temperature, and frequency and duration of excessive temperatures (above the acceptable temperature). CIBSE Guide A (CIBSE 2007) suggests in summer time $25^{\circ} \mathrm{C}$ may be acceptable where fewer people will be uncomfortable. However for dwellings, recommended temperature level is $25^{\circ} \mathrm{C}$ for living rooms and $23^{\circ} \mathrm{C}$ for bedrooms. Sleep may be impaired at temperatures above $24^{\circ} \mathrm{C}$.

For residential buildings CIBSE recommended benchmark peak temperature of $28^{\circ} \mathrm{C}$ for living spaces and $26^{\circ} \mathrm{C}$ for bedrooms. The building will be overheated when peak temperature exceeds more than $1 \%$ of annual occupied hours above $26^{\circ} \mathrm{C}$ for bedrooms and $28^{\circ} \mathrm{C}$ for living rooms.

\section{ADAPTIVE COMFORT STANDARDS}

Other than the recommended temperature benchmarks from guides, the adaptive comfort index pro- vides a wider acceptable range of temperatures for occupants. Adaptive comfort standards indicate the degree of dissatisfaction of the occupants not only based on the current temperature, but also on the thermal environment experienced in previous few days.

Adaptive comfort standards have been generated by statistical analysis of collected data over a long period of time from various locations of the world. This has caused variations in the quality of data and analysis methods proposed by various researchers. Although key principles are same, ASHRAE (2010) and BS/CIBSE have different adaptive thermal comfort standards. As this has been a widely accepted standard and included in the international and national standards, it is necessary to identify the adaptive comfort standards for future climate, and explore the extent of adaptation opportunity occupants require. In this study adaptive thermal comfort ranges have been calculated based on BS 15251 (BS 2007).

The following equation was used to determine the running mean of outdoor temperature,

$$
\theta_{\mathrm{RM}}=(1-\alpha)\left\{\theta_{\mathrm{ed}-1}+\alpha \cdot \theta_{\mathrm{ed}-2}+\alpha^{2} \theta_{\mathrm{ed}-3} \cdots \cdot\right\}
$$

where $\theta_{R M}$, is the running mean temperature in ${ }^{\circ} \mathrm{C}$ for the day under investigation, $\theta_{\text {ed- }}$ is the daily mean external temperature $\left({ }^{\circ} \mathrm{C}\right)$ for the previous day; $\theta_{\text {ed }} 2$ is the daily mean external temperature $\left({ }^{\circ} \mathrm{C}\right)$ for the previous day and $\alpha$ is is a constant between 0 and 1 , and recommended to use 0.8 .

Outdoor running mean temperature ( $\theta R M)$ was calculated considering previous 7 days by applying Equation 3. $\theta_{\text {ed- } 1}$ to $\theta_{\text {ed- }-7}$ was calculated using temperature data from CIBSE DSY weather files, and $\mathbf{\alpha}=0.8$ was used. Adaptive comfort bands were calculated by applying in Equations (4) and (5) for upper and lower values of the band respectively.

$$
\begin{aligned}
& \theta_{\mathrm{U}}=0.33 \theta_{\mathrm{RM}}+18.8+\theta_{\mathrm{R}} \\
& \theta_{L}=0.33 \theta_{\mathrm{RM}}+18.8-\theta_{\mathrm{R}}
\end{aligned}
$$

where, $\theta_{U}$ is the upper limit and $\theta_{L}$ is the lower limit of the adaptive comfort band in ${ }^{\circ} \mathrm{C}$. $\theta_{R}$ is the distance between the thermally neutral temperature and upper or lower values of adaptive comfort bands. $\theta_{R}$ varies depending on the application of the index. For example, $\theta_{R}$ of $2^{\circ} \mathrm{C}$ refers to catego- 
ry I of adaptive comfort index in BS 15251 and corresponds to less than $6 \%$ Percentage People Dissatisfied (PPD), $\theta_{R}$ for category $\|$ is $3^{\circ} \mathrm{C}$ and corresponds to less than $10 \%$ PPD.

\section{RESULTS AND ANALYSIS}

\section{PERFORMANCE IN PRESENT CLIMATE}

Figure 2(a) presents the current climate (1990s) hour by hour temperature distribution of four regional cities. The result shows that London and Birmingham have higher tendencies of suffering with temperatures over the acceptable comfort limit $\left(23^{\circ} \mathrm{C}\right)$. Figure 3 describes the annual percentage of occupied hours (1800 to 0800), which remain above $23^{\circ} \mathrm{C}, 24^{\circ} \mathrm{C}$ and $26^{\circ} \mathrm{C}$ for ground floor bedroom. These results show that the London is marginally falling into the CIBSE overheating criteria (annual $1.13 \%$ of occupied hours). The temperature remains over $24^{\circ} \mathrm{C}$ for a considerable period of time during peak summer, which is $4.69 \%$ of annual occupied hours. Total hour over acceptable operative temperature $\left(23^{\circ} \mathrm{C}\right.$ ) is 952 (39 days) among which 589 hours are within occupied hours. Birmingham has 183 hours ( 8 days) over $23^{\circ} \mathrm{C}$ among which 119 hours are occupied. The longest duration temperature remains above $26^{\circ} \mathrm{C}$ is approximately 4.8 days continuously (Table 2). Table 2 shows that number of occurrences (frequency) of high temperature and maximum duration are higher in southern half of the country as expected.

\section{PERFORMANCE IN FUTURE CLIMATE}

Results show that London is already falling within the overheating criteria defined by CIBSE. In 2020s this rises to $2.13 \%$ for London and $1.11 \%$ for Birmingham. This stipulates that Birmingham has strong bias to be overheated during 2020s. In 2050 s not surprising that annual percentage of occupied hours above $26^{\circ} \mathrm{C}$ will rise well above $1 \%$ for three cities: London (7.34\%), Birmingham (1.53\%) and Manchester (1.50\%) (Figures 2 and 3).

Average temperatures of the 4 bedrooms of the selected study for different periods are presented in Table 3. The results showed that the aver-

\begin{tabular}{|c|c|c|c|c|c|c|}
\hline & \multicolumn{2}{|c|}{ Above $23^{\circ} \mathrm{C}$} & \multicolumn{2}{|c|}{ Above $24^{\circ} \mathrm{C}$} & \multicolumn{2}{|c|}{ Above $26^{\circ} \mathrm{C}$} \\
\hline & Erequency & $\begin{array}{c}\text { Max. } \\
\text { duration } \\
\text { (hours) }\end{array}$ & Frequency & $\begin{array}{l}\text { Max. } \\
\text { duration } \\
\text { (hours) }\end{array}$ & Frequency & $\begin{array}{l}\text { Max. } \\
\text { duration } \\
\text { (hours) }\end{array}$ \\
\hline London & 34 & 235 & 4 & 97 & 4 & 74 \\
\hline Birmingham & 10 & 160 & 2 & 115 & 7 & 15 \\
\hline Manchester & 22 & 124 & 7 & 72 & 3 & 12 \\
\hline Edinburgh & 7 & 75 & 2 & 82 & 1 & 25 \\
\hline
\end{tabular}

\begin{tabular}{|c|c|c|c|c|}
\hline Year & London & Birmingham & Manchester & Edinburgh \\
\hline 1990 & 20.63 & 18.70 & 18.58 & 16.89 \\
2020 & 21.78 & 19.76 & 19.50 & 17.70 \\
2050 & 23.06 & 20.93 & 20.53 & 18.60 \\
2080 & 24.95 & 22.65 & 22.41 & 19.91 \\
\hline
\end{tabular}

table 3. Average temperature of bedrooms in different climatic conditions and locations.

age increment of indoor operative temperature ranges from $1.15^{\circ} \mathrm{C}$ (from 1990 to 2020) to $1.89^{\circ} \mathrm{C}$ (2050 to 2080), which shows non-linear trends of temperature rises from present time to the end of the century.

\section{EVALUATION OF ADAPTIVE THERMAL COMFORT RANGES}

Results show variable temperature ranges as comfort criteria for selected 4 cities. Table 4 presents the upper limit of category II adaptive comfort range of these locations. Results show that London has higher adaptive comfort upper limit compared to other cities. For both London and Birmingham this is above the CIBSE recommended $26^{\circ} \mathrm{C}$ maximum temperature benchmark to predict overheating criteria. This can indicate that using the adaptive comfort bands for cooling purposes (for mechanically cooled buildings) can consume lower energy compared to recommended temperature benchmark overheating.

\begin{tabular}{|c|c|c|c|c}
\hline & 1990 & 2020 & 2050 & 2080 \\
\hline London & 28.10 & 28.32 & 28.73 & 29.32 \\
\hline Birmingham & 27.59 & 27.79 & 28.17 & 28.72 \\
\hline Manchester & 24.33 & 24.54 & 24.92 & 25.47 \\
\hline Edinburgh & 23.72 & 23.89 & 24.18 & 24.61 \\
\hline
\end{tabular}

Table 4. Adaptive comfort range (category II) upper limit. 

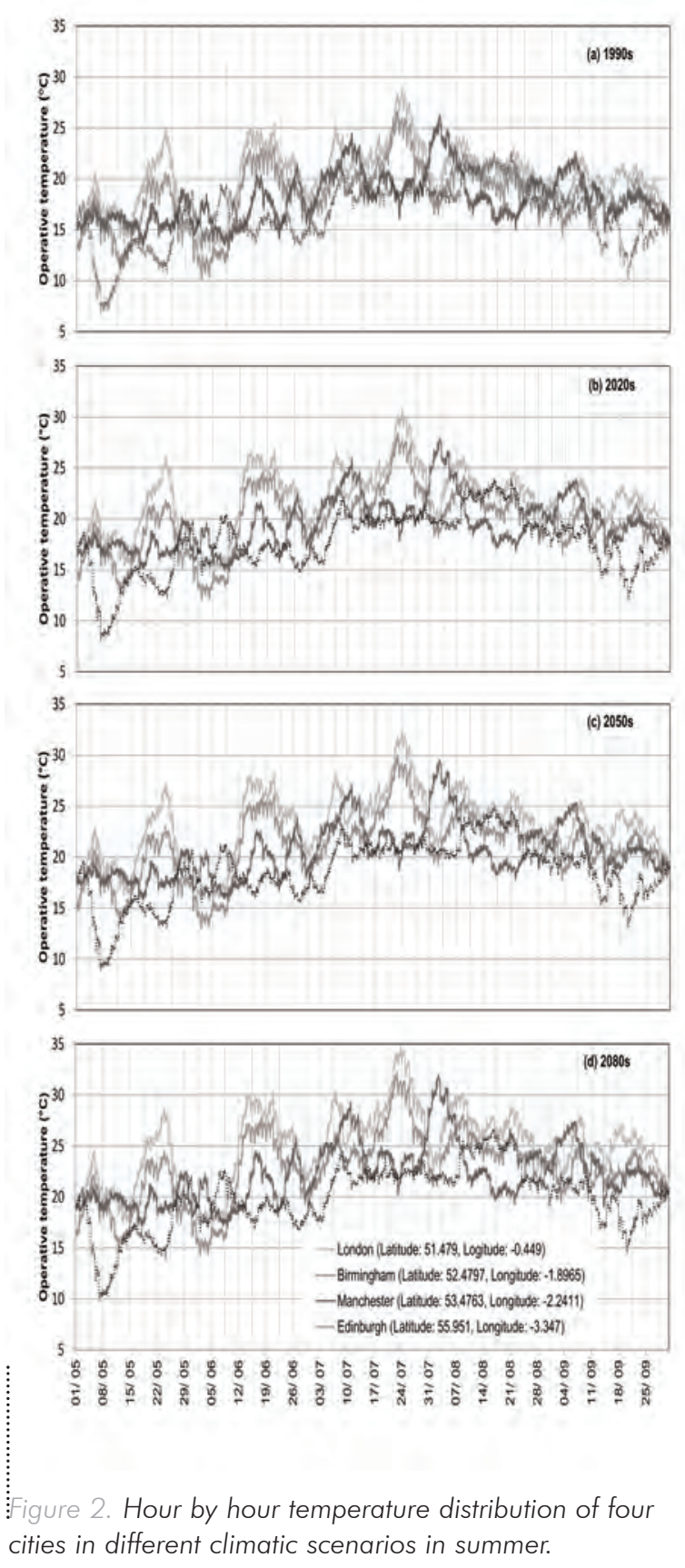

In London although most of the time operative temperature remains within the category II comfort band, sudden peak is seen in the month of July rising above $4^{\circ} \mathrm{C}$ in 1990s (Figure 4a). The tendency of remaining above category II thermal comfort band becomes higher in future climates, where it remains above the comfort band for $1.35 \%$ of annual occupied hours in 2020s (Figure 4a, 4b and 4c). In 2020s and 2050s the maximum difference between the adaptive comfort neutral temperature and the operative temperature is $5.6^{\circ} \mathrm{C}$ and $6.9^{\circ} \mathrm{C}$ respectively. This can stipulate that even for short period peak temperature can go well beyond acceptable limit and cause extreme thermal dis- comfort. Similar trend is also seen for Birmingham during 2050s, where more than $1.22 \%$ of annual occupied hour remain above the upper limit of the comfort band (Figure 5 and Figure 6).

Again building guides suggest (CIBSE 2005, 2006; BS 2007) when indoor operative temperature is above $25^{\circ} \mathrm{C}$, air velocity can be increased to compensate the high temperature. In this case the maximum temperature can be increased to few degrees provided adequate air velocity has been achieved. This indicates the provision of increasing air velocity (by fans or natural ventilation) should be a key point in future design recommendations.

\section{IMPACT OF AIR CHANGE RATE (ACH)}

All data presented so far are with an average $\mathrm{ACH}$ of 2 for the bedrooms. It is obvious that $\mathrm{ACH}$ can have significant impact on the thermal performance of the building, where increased $\mathrm{ACH}$ will help in maintaining the indoor operative temperature within the comfort range in hot weather. A comparison of variable $\mathrm{ACH}$ and indoor temperature performance is presented in Figure 7 for Birmingham and London.

Results show that a minimum of $4 \mathrm{ACH}$ can reduce the overheating criteria within the acceptable range for Birmingham in 2050s. However to maintain the overheating criteria in 2080 air change rate as high as 10 is not enough, and leaving $1.41 \%$ of annual occupied hours over $26^{\circ} \mathrm{C}$. For London a minimum of $6 \mathrm{ACH}$ is expected to prevent overheating in 2020s, however this might not enough after this period. This indicates that additional adaptation measures are necessary for London area well before 2050s compared to other parts of the country.

Again user behaviour associated with ventilation can have an impact on the thermal performance of the building. A comparison of 3 scenarios of window opening duration $(8,15$ and 24 hours/day considering $6 \mathrm{ACH}$ for Bedroom 1 ) during hot weather (May to September) are investigated in the study. Results identified that, opening duration ranging from 8 hour to 24 per day can reduce the annual duration of excessive temperature (over $23^{\circ} \mathrm{C}$ ) by 286 hours ( 11 days) for London area by 2050 . 

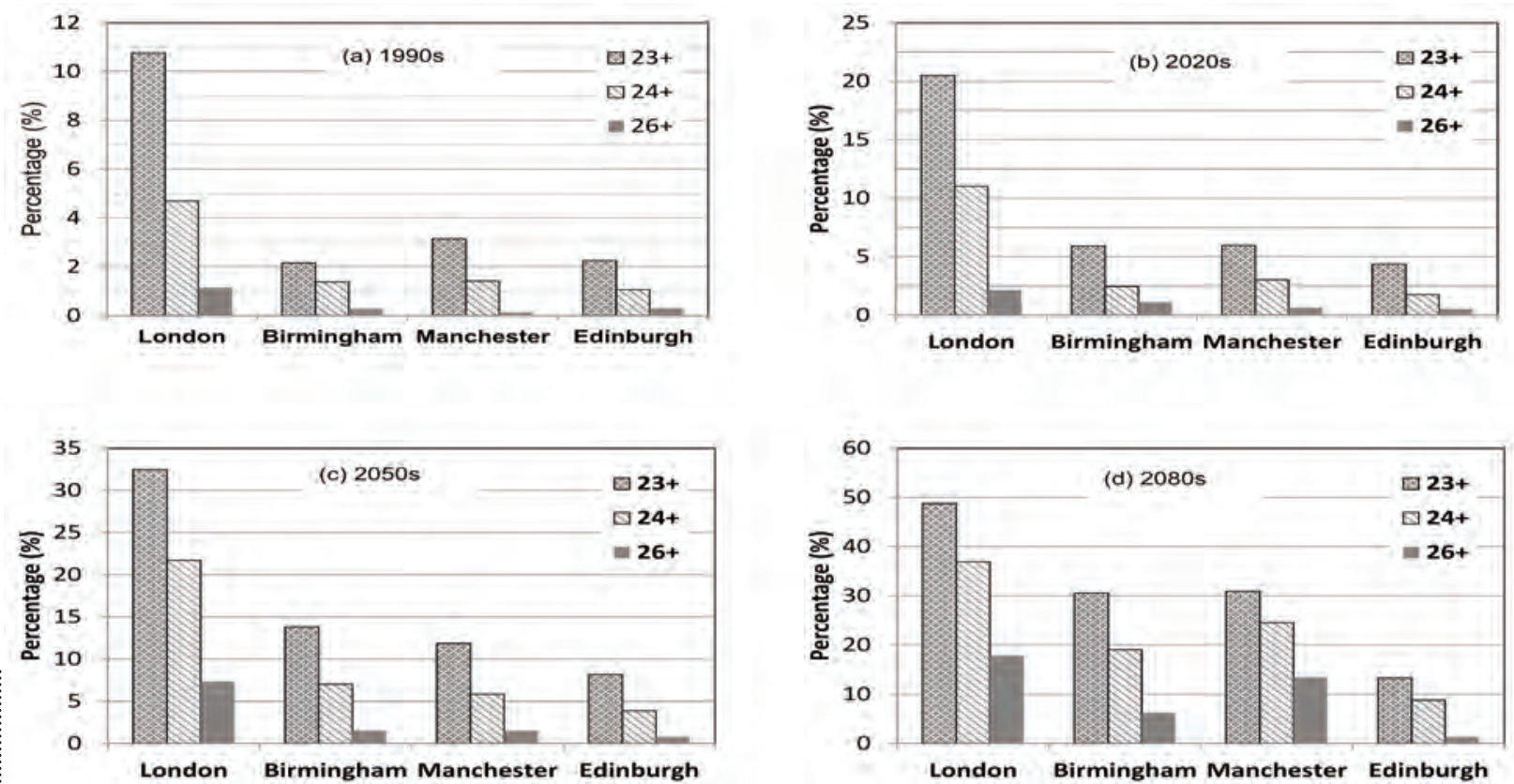

Figure 3. Annual percentage of occupied hours above temperature benchmarks.
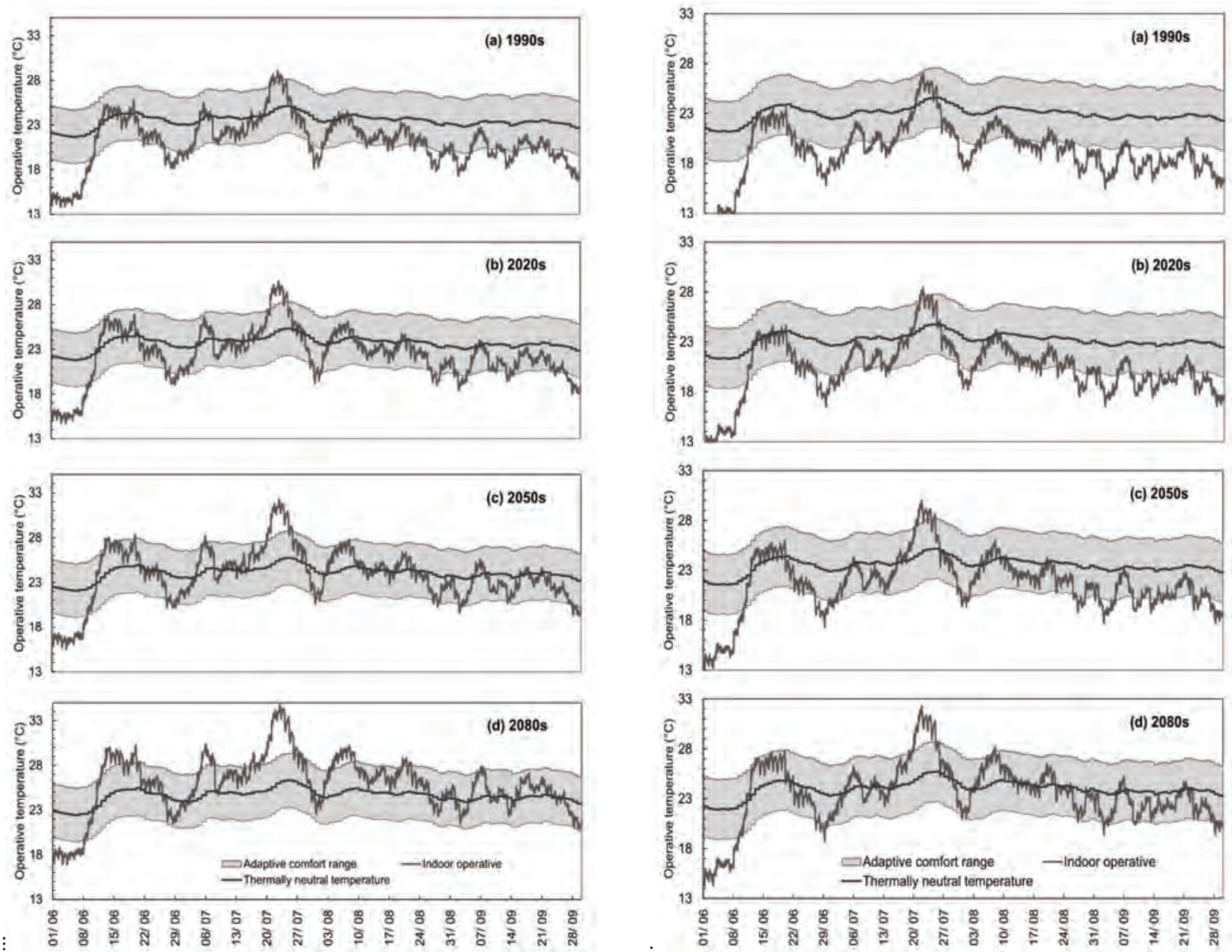

Figure 4. : Adaptive comfort range and indoor operative temperature for 1990s (a), 2020s (b), 2050s (c) and 2080s (d) for London.

Figure 5. Adaptive comfort range and indoor operative temperature for 1990s (a), 2020s (b), 2050s (c) and 2080s (d) for Birmingham. 

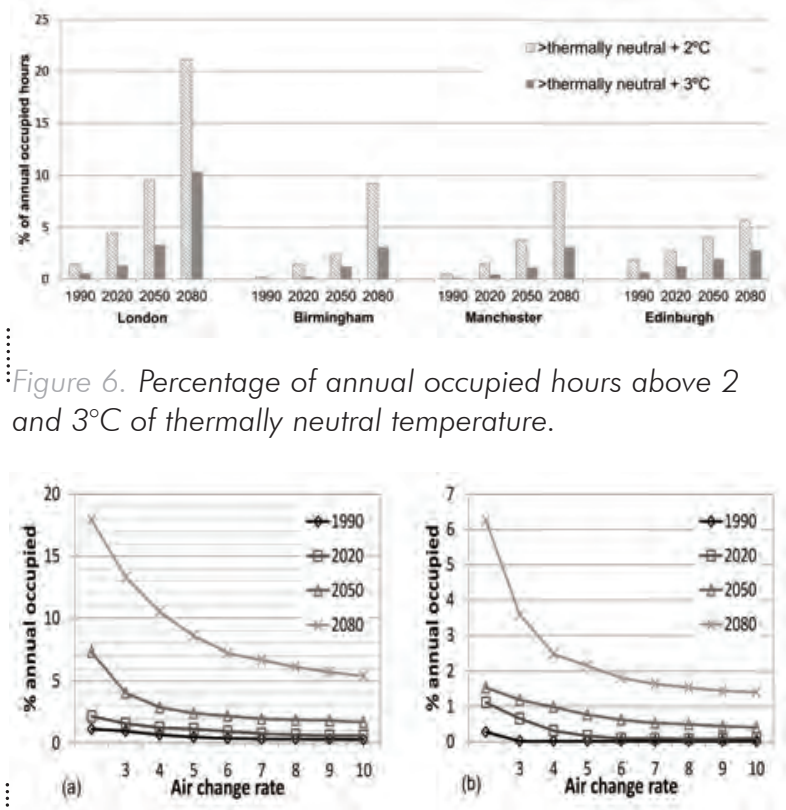

Figure 7. Impact of air change rate in percentage of annual occupied hours for London (a) and Birmingham (b) in four climatic scenarios.

\section{DISCUSSION}

This study presented a computer simulation based evaluation of thermal performance of a multi-occupancy dwelling located in four regional cities in Britain in four time slices. Computer simulation is proved to be an efficient method for assessing environmental performance of buildings, including lighting, thermal, airflow, energy consumption, etc. (Mourshed et al. 2003b; Shikder et al. 2009) and recommended for demonstrating compliance with building regulations (CIBSE 2006).

The study clearly identified that thermal performance of a similar building can vary considerably in different regions. The findings highlight two key issues: dwellings need to adapt to cope with future climatic scenarios; and specific design guidelines/strategies are required for specific regions. Only satisfying the requirements of current building regulations may not lead to an adaptable design, even for a particular region. Underperforming designs can lead to increased energy consumption and discomfort, and can be a burden over time - making the building inhabitable without the aid of mechanical cooling system. This suggests the necessity of developing region specific design guidelines.

Adaptive standards are now considered as part of the key international and national building standards (BS 2007; ASHRAE 2010); hence includ-

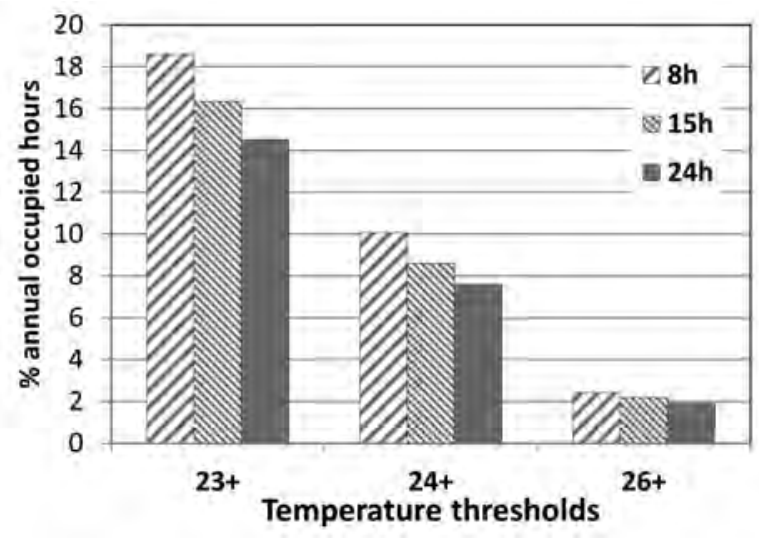

Figure 8. Thermal performance comparison of variable window opening duration.

ing this index into the evaluation process is recommended. However this process needs careful assessment of the extent of adaptation opportunities available for the occupants. Higher temperature will require increased air velocity to keep occupants within the comfort zone. There can be question of how much air velocity is required to compensate the high temperature, as previous studies have identified that increasing the air velocity within the comfort zone are exponentially related with the temperature increment (deDear and Brager 1998). It is, however, evident that occupants will require a higher degree of adaptive opportunities to increase indoor air speed in future climate.

Ventilation of the building plays an important role in increasing indoor airflow and controlling temperature within the comfort range. Results identified that providing only $6 \mathrm{ACH}$ (recommended by CIBSE) might not be enough for London area in 2020s and may require higher ventilation opportunities and other adaptation measures. However, improving the overall ventilation performance might demand additional change or refurbishment to existing buildings as it is highly dependent on the size of the aperture, outside wind velocity and ventilation strategy. This can pose challenge for many existing buildings and there can be question to what extent older buildings can adapt to this strategy. The situation becomes challenging in dense urban areas where outside wind velocity is low. It can be recommended that architects/designers should consider the provision of natural ventilation prospects while designing new dwellings. With a changing climate, provision of cross ventilation seems necessary in future, specifically for the southern half of the country.

Personal adaptive behaviour associated with ventilation can also have an impact on the 


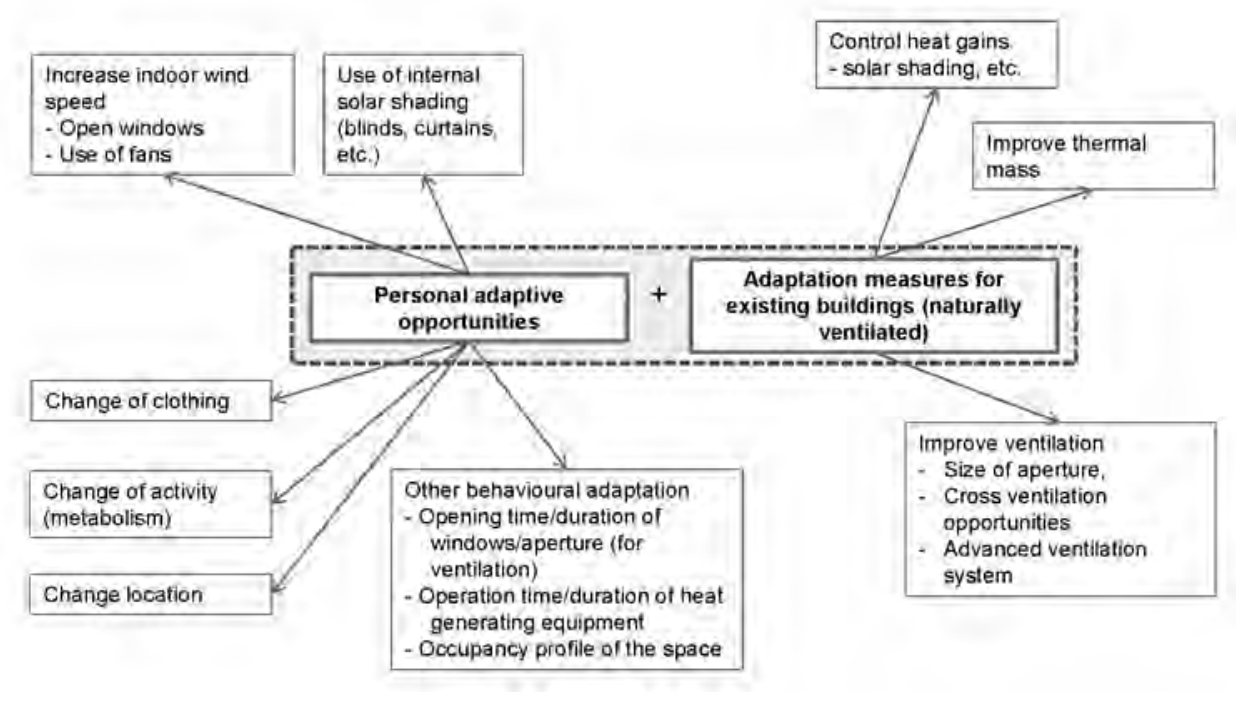

Figure 9. Various personal adaptive opportunities and building adaptation measures for existing naturally ventilated buildings due climate change overheating.

overall thermal performance of the building. Keeping the window open for longer in a day can reduce the duration of overheating during hot weather (Figure 8). Although this study has investigated a single adaptive opportunity, there are number of other personal and behavioral adaptive opportunities that can impact on occupants' thermal experience. It is evident that a combination of personal and building adaptation will be able to minimize the impact of overheating in future climate.

Figure 9 demonstrates that solutions for climate change adaptation to maintain acceptable indoor environment involve the consideration of multi-disciplinary aspects. Evidence also suggests that indoor environment requirement can vary for specific group of people (e.g. ageing population) depending on their physical and psychological condition (Shikder et al. 2012). To develop appropriate modelling and simulation approach of the scenario, it is necessary to acquire a robust understanding of the human behavioural, physical and psychological aspects, and other building physical parameters involved in the process. In addition, the application of advanced computer visualization and optimization techniques can enhance the decision making process of such multi-disciplinary design problems (Mourshed et al. 2003a, Mourshed et al. 201 1, Shikder et al. 2010). Scope remains for further research on how to model and optimize the climate change adaptation strategies that integrates various personal and building adaptation opportunities.

\section{CONCLUSION}

To minimize the impact of overheating risks in future climate, design recommendations with adequate adaptation strategies are required for specific regions rather than a single standard for the whole country. This study identified that average indoor operative temperature of multi-occupancy newbuild residential buildings can increase by around $1.89^{\circ} \mathrm{C}$ by the end of the century in medium emission scenario. This trend of temperature rise can cause an excess of around $6.9^{\circ} \mathrm{C}$ in $2050 \mathrm{~s}$ for London than adaptive comfort neutral temperature of that time, which indicates the maximum temperature can go well beyond acceptable temperature limits even for short or specific period of the year and render the dwelling inhabitable. Such situation will require either mechanical cooling system and/or additional adaptation strategies.

The study also identified that the indoor thermal comfort is also influenced by the duration of window opening (ventilation) in a day. Keeping the window open for longer period proved to be effective in minimizing the overall temperature rise during summer period. Windows open for 24 hour in hot weather can reduce the annual duration of excessive temperature (over $23^{\circ} \mathrm{C}$ ) by 286 hours compared to windows open for only 8 hours for London area in 2050s. Therefore, opportunities for better ventilation are a key adaptive measure to face the challenge of overheating in future.

Finally the study highlighted the complex relationships between various adaptive opportunities to compensate the high temperature in future. Although this study has discussed about the 
prospect of ventilation only, other passive design features and adaptation strategies should be also considered to minimise the impact of hot weather in combination with personal adaptive opportunities. Further studies should focus on identifying the combinatorial solution of various adaptive measures to optimise design strategies to mitigate overheating in future.

\section{REFERENCES}

ASHRAE 2010, Thermal environmental conditions for human occupancy, American Society of Heating, Refrigerating and AirConditioning Engineers, Atlanta, GA.

AUTODESK 2012, Autodesk Ecotect analysis: Sustainable building design, [Computer program] Autodesk Inc., San Rafael, CA.

BS 2007, Indoor environmental input parameters for design and assessment of energy performance of buildings addressing indoor air quality, thermal environment, lighting and acoustics, British Standards, UK.

CIBSE 2005, Climate change and the indoor environment: Impacts and adaptation,

Chartered Institution of Building Services Engineers, London, UK.

CIBSE 2006, Environmental design: Guide A, Chartered Institution of Building Services Engineers, London, UK.

DE DEAR R.J., BRAGER, G.S. 1998, Developing an adaptive model of thermal comfort and preference, ASHRAE Transactions, 104:1, 145-167.

DE WILDE, P., TIAN, W. 2010, The role of adaptive thermal comfort in the prediction of the thermal performance of a modern mixed-mode office building in the UK under climate change, Journal of Building Performance Simulation, 3:2, 87 . 101.

DE WILDE, P., TIAN, W. 2012, Management of thermal performance risks in buildings subject to climate change, Building and Environment, 55, 167-177
DCLG 2009, Housing and planning statistics, Department of Communities and Local Government, London, UK.

GUPTA, R. and GREGG, M. 2012, Using UK climate change projections to adapt existing English homes for a warming climate, Building and Environment, 55, 20-42.

HAMILTON-MACLAREN, F., LOVEDAY, D. L. and MOURSHED, $M$. (in press) Public opinions on alternative lower carbon wall construction materials for UK housing, Habitat International. DOI: 10.1016/j.habitatint.2011.12.015.

HOLMES, M. and HACKER, J. 2007, Climate change, thermal comfort and energy: Meeting the design challenges of the $27^{\text {st }}$ century, Energy and Buildings, 39:7, 802-814.

JENTSCH, M.F., BAHAJ, A.S. and JAMES, P.A.B. 2008, Climate change future proofing of buildings - Generation and assessment of building simulation weather files, Energy and Buildings, 40:12, 2148-2168.

LOMAS, K.J. and GIRIDHARAN, R. 2011 Thermal comfort standards, measured internal temperatures and thermal resilience to climate change of free-running buildings: A casestudy of hospital wards, Building and Environment, 55, 57-72.

MOURSHED, M.M., KELLIHER, D. and KEANE, M.M. 2003a, ArDOT: A tool to optimize environmental design of buildings, in: Proceedings of the 8th International IBPSA Conference. 11 14 August, Eindhoven, Netherlands, 919-926.

MOURSHED, M.M., KELLIHER, D. and KEANE, M. 2003b, Integrating building energy simulation in the design process, IBPSA News, 13:1, 21-26.

MOURSHED, M., KELLIHER, D., KEANE, M. 2005, Green architecture: The need for climate analysis and thermal simulation during early stages of design, Global Built Environment Review, 5(2), 12-20.

MOURSHED, M. 2011, The impact of the projected changes in temperature on heating and cooling requirements in buildings in Dhaka, Bangladesh, Applied Energy, 88:11, 3737 3746 .

MOURSHED, M., SHIKDER, S. and PRICE, A. 201 1, Phi-array: A novel method for fitness visualization and decision making in evolutionary design optimization, Advanced Engineering Informatics, 25:4, 676-687.

MURPHY, J.M., SEXTON, D.M.H., JENKINS, G.J. et al. 2009, UK Climate Projections Science Report: Climate change projections, Met Office, Exeter, UK. 
NBS 2010, The Building Regulations 2000: Approved Document LIA: Conservation of fuel and power, HM Government National Building Specification, UK.

NICOL, J.F. and HUMPHREYS, M.A. 2002, Adaptive thermal comfort and sustainable thermal standards for buildings, Energy and Buildings, 34:6, 563-572.

SHIKDER, S., PRICE, A. and MOURSHED, M. 2009, Evaluation of four artificial lighting simulation tools with virtual building reference, in: M. AlAkaidi (ed), Proceedings of European Simulation and Modelling Conference, EUROSISETI, 26-28 October Leicester, UK, 77-82.

SHIKDER, S., MOURSHED, M. and PRICE, A. 2010, Luminaire position optimisation using Radiance based simulation: A test case of a senior living room, in: W Tizani (ed), Proceedings of the International Conference on Computing in Civil and Building Engineering (ICCCBE-2010), 30 June-2 July, Nottingham, UK, 379.

SHIKDER, S., MOURSHED, M. and PRICE, A. 2012, Therapeutic lighting design for the elderly: A review, Perspectives in Public Health, 132:6, DOI: $10.1177 / 1757913911422288$.

\section{Author(s):}

\section{Shariful Shikder}

School of Civil and Building Engineering

Loughborough University

Loughborough, Leicestershire

LE 11 3TU, UK

Email:s.h.shikder@lboro.ac.uk

\section{Monjur Mourshed}

School of Civil and Building Engineering

Loughborough University

Loughborough, Leicestershire

LE 11 3TU, UK

Email: M.M.Mourshed@lboro.ac.uk and

monjur@mourshed.org

Web: http://monjur.mourshed.org/

\section{Andrew Price}

School of Civil and Building Engineering

Loughborough University

Loughborough, Leicestershire

LE 11 3TU, UK 